DOI: https://doi.org/10.47405/mjssh.v6i10.1100

\begin{tabular}{|c|c|}
\hline & Malaysian Journal of Social Sciences and Humanities (MJSSH) \\
\hline Malaysian Journa of & Volume 6, Issue 10, October 2021 \\
\hline (Mus. SSH) & e-ISSN : 2504-8562 \\
\hline & $\begin{array}{l}\text { Journal home page: } \\
\text { www.msocialsciences.com }\end{array}$ \\
\hline
\end{tabular}

\title{
Kesihatan Mental dan Motivasi Pelajar Semasa Pembelajaran Dalam Talian Sepanjang Pandemik Covid-19
}

\author{
Haizvanie Muhamed Ganasan ${ }^{1}$, Norzaini Azman ${ }^{1}$ \\ 1Fakulti Pendidikan, Universiti Kebangsaan Malaysia (UKM), Malaysia \\ Correspondence: Haizvanie Muhamed Ganasan (p103695@siswa.ukm.edu.my)
}

\begin{abstract}
Abstrak
Kajian ini bertujuan untuk mengenal pasti hubungan antara tahap kesihatan mental dan tahap motivasi dalam kalangan pelajar sarjana Fakulti Pendidikan, di sebuah universiti penyelidikan di Lembah Klang semasa pembelajaran dalam talian dijalankan sepanjang pandemik Covid-19. Kajian berbentuk kuantitatif ini menggunakan kaedah tinjauan deskriptif melalui soal selidik. Kaedah persampelan rawak bersistematik telah digunakan untuk mendapatkan 242 orang pelajar sarjana dari Fakulti Pendidikan, UKM sebagai sampel kajian. General Health Questionnaire (GHQ-12) digunakan bagi mengukur tahap kesihatan mental pelajar sementara Motivated Strategies for Learning Questionnaire (MSLQ) digunakan untuk mengukur tahap motivasi pelajar. Data yang diperoleh dianalisis menggunakan statistik deskriptif dan inferensi. Dapatan kajian mendapati bahawa pelajar sarjana mempunyai tahap kesihatan mental yang rendah (baik) dan tahap motivasi yang tinggi semasa mengikuti pembelajaran dalam talian sepanjang pandemik Covid-19. Hasil kajian turut menunjukkan hubungan yang signifikan dan positif antara kesihatan mental dan motivasi dalam kalangan pelajar sarjana semasa pembelajaran dalam talian sepanjang pandemik Covid-19. Kajian yang dijalankan ini diharap dapat memberi sumbangan kepada pelajar, pensyarah dan Institusi Pengajian Tinggi (IPT) dalam memahami kepentingan menjaga kesihatan mental yang baik semasa pandemik. Dapatan kajian ini memberi implikasi bahawa komunikasi yang lebih luas dan berkesan diperlukan untuk mengurangkan masalah kesihatan mental dan meningkatkan motivasi dalam kalangan pelajar.
\end{abstract}

Kata kunci: kesihatan mental, motivasi, pembelajaran dalam talian, pandemik Covid-19

\section{Students Mental Health and Motivation During Online Learning Throughout Covid-19 Pandemic}

\begin{abstract}
This study aims to identify the relationship between the level of mental health and motivation among postgraduate students from the Faculty of Education in a research university in the Klang Valley area during online learning throughout Covid-19 pandemic. This study uses a quantitative case study approach with a descriptive survey method. A systematic random sampling method was used to obtain a sample of 242 postgraduate students for the study. Students' mental health was measured using the General Health Questionnaire (GHQ-12) and their motivation was assessed using the Motivated Strategies for Learning Questionnaire (MSLQ). The data gathered was analyzed using descriptive and inferential statistics. Findings of the study show that the postgraduate students have low levels of mental health but high levels of motivation during online learning throughout the Covid-19 pandemic. The results of the study also indicated a significant positive relationship between mental health and
\end{abstract}


motivation. These findings contribute to students' and lecturers' understanding of the importance of maintaining good mental health during a pandemic. The findings have implications on the need for broader and effective communication in order to keep and sustain healthy students' mental health and motivation.

Keywords: mental health, motivation, online learning, Covid-19 pandemic

\section{Pengenalan}

Pandemik Covid-19 telah menjadi isu kesihatan global dan memberi impak yang besar kepada sektor pendidikan. Virus Covid-19 mula dikesan di Malaysia pada Januari 2020 dan mula merebak dalam masyarakat tempatan pada bulan Mac 2020 (Muhammad Irfan et al., 2020; Azman \& Abdullah, 2021). Setelah beberapa minggu kemudian, pada 18 Mac 2020, Perintah Kawalan Pergerakan (PKP) di seluruh negara diisytiharkan bertujuan untuk mengawal wabak ini. Pertubuhan Kesihatan Sedunia (WHO) telah mencadangkan kepada masyarakat umum dan institusi pendidikan untuk menghentikan semua aktiviti (Ana et al., 2020; Azman \& Abdullah, 2021). Selaras dengan pengisytiharan ini, sektor pendidikan global juga telah ditutup dan pembelajaran dijalankan secara e-pembelajaran atau dalam talian. Kesemua Institusi Pengajian Tinggi (IPT) telah menggunakan pembelajaran dalam talian sebagai satu-satunya platform untuk meneruskan proses pengajaran dan pembelajaran (PdP) bagi membantu pelajar menghadapi cabaran belajar tanpa bersemuka.

United Nations Educational, Scientific and Cultural Organization atau lebih dikenali sebagai UNESCO, menegaskan bahawa pandemik Covid-19 telah mengganggu proses pembelajaran lebih daripada satu bilion pelajar di 129 negara di seluruh dunia (UNESCO, 2020). Walaupun IPT di seluruh dunia telah berpindah ke 'emergency remote teaching' melalui platform dalam talian, ramai pelajar telah terkesan dengan proses pembelajaran cara baharu ini yang seterusnya menimbulkan beberapa masalah psikologi seperti kebimbangan, stres, gangguan emosi, alexithymia dan kemurungan (Abdul Rashid et al., 2020b; Sheela et al., 2020; Ana et al., 2020; Hairani et al., 2021; Aidos et al., 2020; Deblina et al., 2020; Casagrande et al., 2020). Kajian mengenai kesan Covid-19 dan 'lockdown' terhadap pelajar di IPT mendapati rata-rata pelajar mengalami pelbagai masalah psikologi dan kesihatan mental khususnya dalam aspek kebimbangan dan kemurungan (Bao et al., 2020; Wang et al., 2020; Cao et al., 2020; Yang et al., 2020; Gao et al., 2020; Zhang et al., 2020). Sebagai contoh, kajian oleh Odriozola-González et al. (2020) terhadap kesejahteraan psikologi pelajar universiti di Sepanyol semasa pandemik Covid-19 menunjukkan responden mengalami simptom kemurungan, kebimbangan dan stres yang tinggi dan membimbangkan. Di samping itu, kajian oleh Amir et al. (2020) mengenai kesan wabak Covid-19 terhadap kesejahteraan mental menunjukkan bahawa pelajar perubatan di Iran mengalami tekanan, kebimbangan dan kemurungan di tahap tinggi. Dapatan kajian ini selari dengan kajian oleh Marielle et al. (2020), Matthew et al. (2021), Son et al. (2020), Andi Wahyu et al. (2020) dan Khaled et al. (2021) yang mendapati tahap kesihatan mental pelajar universiti sepanjang pembelajaran dalam talian semasa pandemik berada pada tahap yang tinggi. Kajian ini juga merumuskan bahawa institusi kurang memberi perhatian dan fokus kepada aspek psikologi pelajar sehingga memberi impak yang negatif terhadap pembelajaran pelajar semasa Covid-19. Kesihatan mental yang baik amat diperlukan bagi memastikan pelajar mampu meneruskan pembelajaran walaupun secara dalam talian dan berkemampuan dalam beradaptasi dengan norma baharu (Rigotti et al., 2020; Zacher \& Rudolph, 2021; O'Connor et al., 2020). Justeru, sistem pembelajaran dalam talian yang digunakan sepenuhnya untuk menggantikan pembelajaran bersemuka semasa pandemik Covid-19 dikaitkan sebagai faktor utama kepada penurunan tahap motivasi dan keberkesanan pembelajaran pelajar.

Teori jelas menunjukkan pelajar yang mengalami status kesihatan mental yang baik mempunyai motivasi pembelajaran yang lebih tinggi (Yasuhiro \& Su-Hie, 2021). Kesihatan mental telah dibuktikan boleh mempengaruhi motivasi, tumpuan dan interaksi sosial pelajar (Son et al., 2020). Kesihatan mental adalah keupayaan seseorang individu dalam mengawal emosi yang berkait rapat dengan fikiran, perasaan dan tindakannya apabila menghadapi pelbagai situasi (WHO, 2004). Motivasi pula adalah 
kuasa dalaman yang menggerakkan tingkah laku individu bagi mencapai matlamat yang diingini (Gredler et al., 2004). Ahli psikologi dan doktor kesihatan telah melaporkan bahawa kebanyakan pelajar yang mendapatkan perkhidmatan di pusat universiti kaunseling adalah disebabkan kebimbangan yang berterusan (Son et al., 2020). Hal ini sangat jelas kerana kajian-kajian lepas telah membuktikan bahawa peralihan kepada platform e-pembelajaran semasa pandemik telah meningkatkan tekanan dalam kalangan pelajar universiti kerana pelajar masih tidak dapat menyesuaikan diri dengan norma baharu (Sahu, 2020). Dalam pada itu, kajian lepas juga membuktikan bahawa motivasi dapat membantu individu untuk bangkit semula dan beradaptasi dengan persekitaran yang mencabar (Maila, 2021). Intervensi yang efisien dan bersesuaian perlu dilaksanakan bagi membantu pelajar yang mempunyai tahap motivasi yang rendah agar sentiasa bermotivasi semasa menjalani pembelajaran dalam talian sepanjang pandemik.

Berdasarkan perbincangan di atas, jelas menunjukkan bahawa terdapat keperluan untuk melihat sejauh manakah kesihatan mental mempunyai hubungan dengan motivasi pelajar semasa pembelajaran dalam talian dijalankan sepanjang pandemik Covid-19. Memandangkan, kebanyakan kajian lepas kurang membincangkan mengenai kesihatan mental bersama aspek motivasi khususnya di Malaysia dan dalam kalangan pelajar pascasiswazah, maka terdapat keperluan untuk menjalankan kajian ini. Kebanyakan kajian berkaitan kesihatan mental dan motivasi di IPT di Malaysia tertumpu pada pelajar jurusan perubatan dan di peringkat prasiswazah. Kajian ini diharapkan dapat mengisi jurang pengetahuan berkaitan kesihatan mental dan motivasi dalam kalangan pelajar Sarjana Pendidikan di IPT iaitu bakal guru dan pentadbir di Malaysia. Secara spesifik, kajian bertujuan untuk mengenal pasti hubungan antara tahap kesihatan mental dan tahap motivasi dalam kalangan pelajar sarjana di Fakulti Pendidikan, Universiti Kebangsaan Malaysia (UKM), semasa mengikuti pembelajaran dalam talian sepanjang pandemik Covid-19. Tiga objektif kajian adalah seperti berikut:

i. Mengenal pasti tahap kesihatan mental pelajar sarjana UKM semasa pembelajaran dalam talian sepanjang pandemik Covid-19.

ii. Mengenal pasti tahap motivasi pelajar sarjana UKM semasa pembelajaran dalam talian sepanjang pandemik Covid-19.

iii. Mengenal pasti hubungan antara tahap kesihatan mental dengan tahap motivasi dalam kalangan pelajar sarjana UKM semasa pembelajaran dalam talian sepanjang pandemik Covid-19.

\section{Sorotan Literatur}

\section{Pembelajaran Dalam Talian Semasa Pandemik Covid-19}

Pembelajaran secara dalam talian iaitu 'online learning' ditakrifkan sebagai pembelajaran yang menggunakan Teknologi Maklumat dan Komunikasi (ICT) melibatkan dua jenis persekitaran iaitu 'synchronous' atau 'asynchronous' dan menggunakan pelbagai jenis peranti seperti komputer, komputer riba dan telefon bimbit melalui internet (Shivangi, 2020). Terdapat pelbagai platform pengajaran dan pembelajaran dalam talian supaya pelajar tidak ketinggalan dalam proses pembelajaran seperti Zoom Cloud Meeting, Microsoft Team, Google Meet, Google Classroom, Webex, Telegram, Whatsapp dan sebagainya (Mazidah \& Nor Aidawati, 2021). Penggunaan ICT dan strategi pendidikan yang inovatif seperti ini telah mengubah proses PdP daripada bersemuka kepada secara dalam talian. Pembelajaran dalam talian membolehkan pelajar berada di mana sahaja untuk belajar dan berinteraksi dengan tenaga pengajar dan pelajar lain (Shivangi, 2020). Pembelajaran yang mengaplikasikan perkembangan teknologi telah menjadikan pembelajaran dalam talian menjadi lebih mudah. Walau bagaimanapun, pembelajaran dalam talian memberi cabaran kepada golongan pelajar kurang upaya, kurang berkemampuan dan kepada pelajar yang terpinggir untuk mengakses internet semasa pandemik (Mahiswaran et al., 2020; Azman \& Abdullah, 2021).

Kajian menurut Muniroh et al. (2020) dan Shivangi (2020), pembelajaran dalam talian memerlukan proses pembelajaran kendiri iaitu kemahiran pembelajaran sepanjang hayat. Kemahiran ini melibatkan kemampuan pelajar dalam menentukan apa yang perlu dipelajari, pencarian bahan atau maklumat 
untuk dipelajari, memotivasikan diri, berkemahiran dalam pembelajaran kendiri dan juga boleh membuat refleksi terhadap pembelajaran dengan melakukan pentaksiran kendiri atau pelbagai cara yang lain. Justeru, pembelajaran secara dalam talian memerlukan komitmen, disiplin, kerjasama (Amir et al., 2020 \& Mahiswaran et al., 2020), kebolehan, tingkah laku atau sikap, keinginan dan kefahaman (Abdul Rashid et al., 2020a) daripada semua pihak terutamanya pelajar. Oleh itu, pembelajaran dalam talian perlu dirancang, dilaksanakan dan dinilai keberkesanannya dalam usaha untuk mengurangkan masalah yang dihadapi oleh pelajar untuk memaksimumkan hasil pembelajaran yang lebih cemerlang.

\section{Kesihatan Mental}

World Health Organization (WHO) mentakrifkan kesihatan mental sebagai keadaan kesejahteraan di mana individu menyedari kemampuannya sendiri, dapat mengatasi tekanan hidup yang normal, dapat bekerja dengan produktif dan mampu memberi sumbangan kepada masyarakatnya (WHO, 2004). Definisi ini selari dengan definisi oleh Manwell et al. (2015) iaitu kesihatan mental merangkumi faktor biologi, psikologi dan sosial yang menyumbang kepada keadaan mental seseorang dan kemampuan untuk berfungsi dengan baik di dalam pelbagai persekitaran. Silvana et al. (2015) membahagikan kesihatan mental kepada tiga domain iaitu kesedaran diri, (individu dapat memanfaatkan potensi mereka sepenuhnya), menguasai persekitaran dan berautonomi (kemampuan untuk mengenal pasti, menghadapi dan menyelesaikan masalah).

Holmes et al. (2020) mendapati bahawa pandemik Covid-19 telah memberikan kesan yang besar terhadap kesihatan mental seseorang individu seperti tekanan, trauma, kebimbangan dan kemurungan. Kesihatan mental juga mempengaruhi cara seseorang individu membuat keputusan dalam kehidupan, menyelesaikan masalah serta berinteraksi dengan orang lain (Abdul Aziz et al., 2020). Jika seseorang individu mempunyai tahap kesihatan mental yang positif, mereka mampu menghadapi dan menangani tekanan dengan baik. Sehubungan dengan itu, kesihatan mental merupakan faktor penting yang mempengaruhi prestasi, interaksi, motivasi dan kesihatan mental yang rendah boleh mengganggu perhatian pelajar semasa pembelajaran (Shamzaeffa \& Kevin, 2016). Dalam pada itu, Norazila et al. (2018) menyatakan bahawa kegagalan dalam mengurus serta menyesuaikan diri dalam persekitaran yang berbeza mampu memberi tekanan, kebimbangan dan kemurungan dalam diri pelajar. Dapatan kajian ini selari dengan kajian yang dijalankan oleh Norhazirah (2020) dan Izyan Izzati \& Aishah (2020) terhadap pelajar IPT di Malaysia semasa pandemik Covid-19, iaitu pandemik telah memberikan kesan negatif ke atas kesihatan mental dan aspek psikologi pelajar dari segi emosi, perasaan, fikiran, tekanan dan kebimbangan. Selain itu, kesihatan mental yang rendah turut memberi impak kepada tahap motivasi pelajar semasa pembelajaran dalam talian. Justeru, kesihatan mental penting untuk diberi perhatian kerana ia mempengaruhi motivasi, tingkah laku dan corak interaksi seseorang pelajar semasa pembelajaran dalam talian sepanjang pandemik Covid-19.

\section{Motivasi}

Motivasi berasal dari perkataan 'motive' yang bermaksud keperluan, keinginan, kehendak atau dorongan dalam diri individu. Menurut Bernard (1965), motivasi ialah penggerak yang melibatkan proses membangkit, mengekal dan mengawal minat seseorang individu ke arah mencapai matlamat atau kejayaan. Secara ringkasnya, motivasi merupakan proses dalam diri seseorang individu yang mewujudkan tujuan dan memberikan tenaga bagi tingkah laku seseorang (Kimble, 1984).

Teori Determinasi Kendiri oleh Ryan dan Deci (2000) mengklasifikasikan motivasi kepada dua jenis iaitu motivasi intrinsik dan motivasi ekstrinsik. Motivasi intrinsik adalah motivasi yang berpunca daripada pengaruh dalaman seseorang melalui pembelajaran atau pengalaman. Manakala, motivasi ekstrinsik bermaksud motivasi yang wujud dalam diri individu untuk melakukan sesuatu disebabkan oleh faktor luaran kerana ia akan membawa hasil yang dapat dipisahkan seperti pujian, ganjaran, gred, penghargaan dan persaingan. Motivasi intrinsik dan ekstrinsik menghasilkan niat dan perlakuan yang berbeza dan seterusnya mempengaruhi pengalaman dan prestasi pembelajaran (Ryan \& Deci, 2000). Dalam konteks spesifik kepada aktiviti PdP, Pintrich et al. (1991) telah mendefinisikan motivasi intrinsik sebagai hasil usaha dan pola kepercayaan dalam mengekalkan tingkah laku yang berarahkan matlamat dalam usaha mempelajari perkara baharu, rasa ingin tahu terhadap sesuatu yang sukar untuk 
dipelajari, memahami kandungan pelajaran secara menyeluruh dan memilih tugasan kursus yang boleh dipelajari walaupun ia tidak menjamin gred yang baik. Sementara, motivasi ekstrinsik pula adalah kebolehan dan harga diri seseorang individu berdasarkan keinginan untuk mendapatkan gred yang baik dalam program pengajian, meningkatkan keseluruhan gred purata dan keinginan untuk melakukan yang terbaik bagi menunjukkan kemampuan diri kepada keluarga, rakan, pensyarah, penyelia dan orang lain (Pintrich et al., 1991).

Berdasarkan tinjauan literatur, pembelajaran menerusi platform dalam talian didapati memberikan kesan yang positif terhadap motivasi pelajar (Duncan et al., 2012; Giesbers et al., 2013; Yani et al., 2020; Nur Hazirah \& Masayu, 2020; Samir et al., 2020; Zamry et al., 2021 \& Munirah et al., 2021). Maksudnya, motivasi adalah faktor pendorong utama kepada pelajar untuk melibatkan diri secara aktif dalam aktiviti PdP menerusi platform dalam talian (Letchumanan et al., 2020). Pelajar yang bermotivasi tinggi mempunyai keazaman untuk terus mengikuti pembelajaran tanpa gagal kerana mereka mempunyai dorongan yang kuat untuk terus meminati apa yang dipelajari hasil dari rangsangan yang kuat iaitu menerusi insentif dan motif serta lebih inovatif dalam menggunakan teknologi digital semasa pembelajaran (Zaliza \& Zaitul Azma, 2014). Kajian lepas juga membuktikan bahawa motivasi pelajar semasa PdP sama ada secara bersemuka ataupun secara dalam talian dipengaruhi oleh faktor persekitaran iaitu, teknologi dan sikap atau tingkah laku (Bandura, 1971; Deci \& Ryan, 2000; Shivangi, 2020; Abdul Aziz \& Aida Zuraina, 2020; Zamry et al., 2021; Munirah et al., 2021). Rumusan daripada kajian berkaitan mendapati bahawa sikap, tahap kesediaan, persekitaran dan motivasi adalah berkait rapat antara satu sama lain. Perkara ini jelas menunjukkan bahawa pelajar didorong oleh motivasi dalaman dan motivasi luaran sepanjang pembelajaran dalam talian semasa pandemik.

\section{Metod Kajian}

\section{Reka Bentuk Kajian}

Kajian ini berbentuk kajian kes menggunakan kaedah tinjauan deskriptif untuk mendapatkan data jenis kuantitatif menggunakan soal selidik. Soal selidik merupakan instrumen yang kerap digunakan dalam kajian deskriptif kerana mudah untuk memperoleh data daripada responden (Fraenkel \& Wallen, 1993). Menurut Creswell (2014) kaedah kuantitatif merupakan satu pendekatan untuk menguji hipotesis dan menjawab persoalan kajian dengan mengkaji hubungan antara pemboleh ubah.

\section{Lokasi Kajian}

Kajian ini dijalankan di sebuah universiti awam di Lembah Klang iaitu di Universiti Kebangsaan Malaysia (UKM), Bangi, Selangor. Universiti ini dipilih kerana UKM merupakan universiti pertama di Malaysia yang mendapat akreditasi ISO 9000 pada tahun 1998 dan antara salah sebuah universiti yang tergolong dalam kumpulan Universiti Penyelidikan. Pada tahun 2006, UKM diperakui sebagai Universiti Penyelidikan di Malaysia berdasarkan pencapaiannya dalam menghasilkan banyak penyelidikan berkualiti tinggi dan telah mendapat Anugerah Kualiti Perdana Menteri iaitu status SwaAkreditasi (2010) dan status Universiti Autonomi pada Januari 2012. Tambahan, UKM berada di kedudukan ke-141 dalam QS World University Rankings 2020/2021 baru-baru ini dan tempat ke-41 dalam QS Asia University. Fakulti Pendidikan di UKM adalah sebuah fakulti yang ditubuhkan untuk menyediakan tenaga profesional guru dan pentadbir pendidikan yang cekap. Bakal guru dilatih aspek ilmu, kemahiran dan nilai sahsiah agar mereka dapat menjalankan tugas di sekolah untuk melahirkan masyarakat berilmu dalam semua bidang pendidikan yang akhirnya dapat memberikan impak positif dengan menaik taraf pendidikan sekolah. Semasa pandemik Covid-19, proses PdP untuk program sarjana di Fakulti Pendidikan, UKM telah dijalankan dalam talian sepenuhnya.

\section{Populasi dan Sampel Kajian}

Populasi kajian ini adalah pelajar yang mengikuti program Sarjana Pendidikan di Fakulti Pendidikan, UKM. Bilangan populasi pelajar sarjana di Fakulti Pendidikan, UKM ialah seramai 663 orang pelajar. 
Kaedah persampelan rawak bersistematik telah digunakan untuk mendapatkan 242 orang pelajar sarjana dari Fakulti Pendidikan sebagai sampel kajian. Penentuan saiz sampel ini adalah merujuk kepada jadual Krejcie dan Morgan (1970). Berdasarkan persampelan berikut, pengkaji mengedarkan soal selidik secara dalam talian supaya pelajar dapat mengisi borang soal selidik dengan membuka pautan untuk 'Google Form' yang diberi. Kaedah ini digunakan kerana terdapat kekangan dalam mengedarkan soal selidik secara bersemuka semasa pandemik Covid-19.

\section{Instrumen Kajian}

Borang soal selidik yang digunakan dalam kajian ini terdiri daripada tiga bahagian. Bahagian A adalah bertujuan untuk mendapatkan maklumat demografi responden, Bahagian B adalah General Health Questionnaire (GHQ-12) yang dibangunkan oleh Goldberg (1972) dan Goldberg \& Williams (1988) dan Bahagian C pula adalah Motivated Strategies for Learning Questionnaire (MSLQ) oleh Pintrich et al. (1991).

General Health Questionnaire (GHQ-12) yang bertujuan untuk mengukur tahap kesihatan mental telah diterjemahkan dan diadaptasi oleh Muhamad Saiful et al. (2010). Melalui pelbagai ujian kebolehpercayaan soal selidik versi Bahasa Melayu adalah tinggi (Muhamad Saiful et al., 2010; Shamzaeffa \& Kevin, 2016) iaitu sekitar nilai $a=0.85$ - 0.87. Soal selidik ini mengandungi 12 item yang mengukur tiga dimensi iaitu 1) Kebimbangan dan Kemurungan (Anxiety and Depression), 2) Disfungsi Sosial (Social Dysfunction) dan 3) Kehilangan Keyakinan (Loss of Confidence). Di samping itu, GHQ-12 menggunakan skala likert 0 hingga 3 iaitu 0 - tidak langsung, 1- tidak lebih dari biasa, 2 lebih dari biasa dan 3 - sangat lebih dari biasa. Berdasarkan jumlah skor instrumen GHQ-12, jumlah skor 0 hingga 12 berada pada kategori normal, jumlah skor bagi kategori berisiko tinggi ialah 13 hingga 24 dan jumlah skor untuk kategori kes kritikal atau teruk ialah dalam lingkungan 25 hingga 36. Semakin rendah jumlah skor keseluruhan bagi instrumen GHQ-12 semakin baik tahap kesihatan mental pelajar manakala semakin tinggi jumlah skor keseluruhan, semakin membimbangkan tahap kesihatan mental pelajar sepanjang pembelajaran dalam talian semasa pandemik. Jadual 1 menunjukkan dimensi dan bilangan item bagi instrumen GHQ-12.

Jadual 1: Dimensi dan bilangan item bagi instrumen GHQ-12

\begin{tabular}{lcc}
\hline \multicolumn{1}{c}{ Dimensi } & Nombor item & Jumlah \\
\hline Kebimbangan dan Kemurungan & B1, B2, B7, B10 & 4 \\
Disfungsi Sosial & B3, B4, B5, B6, B8, B9 & 6 \\
Kehilangan Keyakinan & B11, B12 & 2 \\
\hline & Jumlah & 12 \\
\hline
\end{tabular}

Motivated Strategies for Learning Questionnaire (MSLQ) di bahagian C mempunyai dua bahagian iaitu Motivasi (31 item) dan Strategi Pembelajaran Pelajar (50 item). Instrumen ini mempunyai kebolehpercayaan yang tinggi iaitu nilai antara $a=0.81$ - 0.90 (Fakhruddin \& Mohd Isha, 2020; Day et al., 2020). Hal ini menunjukkan bahawa MSLQ sesuai digunakan untuk pelajar IPT di Malaysia. Walau bagaimanapun, dalam kajian ini, pengkaji hanya menggunakan 31 item meliputi enam dimensi iaitu 1) Motivasi Intrinsik (Intrinsic Goal Orientation), 2) Motivasi Ekstrinsik (Extrinsic Goal Orientation), 3) Nilai Tugasan (Task Value), 4) Kawalan Kepercayaan Pembelajaran (Control of Learning Beliefs), 5) Efikasi Kendiri Pembelajaran dan Prestasi (Self-Efficacy for Learning and Performance) dan 6) Kebimbangan Ujian (Test Anxiety).

Soal selidik ini menggunakan skala likert tujuh-mata daripada 1 (sangat tidak benar) hingga 7 (sangat benar). Skor bagi setiap item motivasi dibahagikan kepada dua iaitu jumlah skor antara 31 hingga 124 adalah rendah sementara jumlah skor 125 hingga 217 adalah tinggi. Jumlah skor yang rendah menunjukkan tahap motivasi pelajar sarjana semasa pembelajaran dalam talian adalah rendah manakala, jumlah skor yang tinggi bermakna tahap motivasi pelajar sarjana semasa pembelajaran dalam talian sepanjang pandemik adalah tinggi. Jadual 2 menunjukkan dimensi dan bilangan item bagi instrumen MSLQ. 
DOI: https://doi.org/10.47405/mjssh.v6i10.1100

Jadual 2: Dimensi dan bilangan item bagi instrumen MSLQ

\begin{tabular}{lcc}
\hline \multicolumn{1}{c}{ Dimensi } & Nombor item & Jumlah \\
\hline Motivasi Intrinsik & C1, C16, C22, C24 & 4 \\
Motivasi Ekstrinsik & C7, C11, C13, C30 & 4 \\
Nilai Tugasan & C4, C10, C17, C23, C26, C27 & 6 \\
Kawalan Kepercayaan Pembelajaran & C2, C9, C18, C25 & 4 \\
Efikasi Kendiri Pembelajaran dan Prestasi & C5, C6, C12, C15, C20, C21, C29, C31 & 8 \\
Kebimbangan Ujian & C3, C8, C14, C19, C28 & 5 \\
\hline & Jumlah & 31 \\
\hline
\end{tabular}

Seterusnya, Alpha Cronbach digunakan untuk mengukur kebolehpercayaan keseluruhan instrumen. Menurut Hair et al. (2010) Alpha Cronbach merupakan ukuran kebolehpercayaan yang mempunyai nilai berkisar dari sifar hingga satu dan nilai kebolehpercayaan mesti lebih daripada 0.6. Berikut adalah analisis kebolehpercayaan instrumen General Health Questionnaire (GHQ-12) dan Motivated Strategies for Learning Questionnaire (MSLQ) bagi kajian ini. Berdasarkan jadual 3, nilai kebolehpercayaan bagi instrumen GHQ-12 iaitu pemboleh ubah bebas (kesihatan mental) menunjukkan $a=0.79$ sementara, nilai kebolehpercayaan bagi instrumen MSLQ iaitu pemboleh ubah bersandar (motivasi) pula menunjukkan nilai $a=0.91$. Secara keseluruhan, analisis menunjukkan bahawa kesemua item mempunyai nilai kebolehpercayaan yang tinggi dan telah mencapai konsistensi dalaman yang ditetapkan (Sekaran \& Bougie, 2013).

Jadual 3: Nilai kebolehpercayaan bagi instrumen GHQ-12 dan MSLQ

\begin{tabular}{cccc}
\hline Pemboleh Ubah & No item & Bilangan Item & Nilai Alpha Cronbach \\
\hline $\begin{array}{c}\text { Kesihatan Mental } \\
\text { (GHQ-12) }\end{array}$ & B1-B12 & 12 & 0.79 \\
Motivasi (MSLQ) & C1-C31 & 31 & 0.91 \\
\hline
\end{tabular}

\section{Analisis Data}

Data kajian yang diperoleh dianalisis dengan menggunakan perisian Statistical Package for Social Science Version IBM (SPSS), versi 26 (2020). Statistik deskriptif (min dan sisihan piawai) dan inferensi (Korelasi Pearson) digunakan untuk menganalisis data-data yang diperoleh. Analisis data bagi kajian ini merangkumi keseluruhan soal selidik yang terdiri daripada Bahagian A (demografi responden), Bahagian B (GHQ-12) dan Bahagian C (MSLQ). Statistik deskriptif merupakan pengumpulan, penggabungan dan penyajian data termasuk sisihan piawai, nilai minimum dan maksimum yang dihitung untuk mengira informasi berkaitan dengan demografi responden (Bluman, 2017). Analisis frekuensi atau kekerapan dan peratusan digunakan untuk menjelaskan profil responden. Sementara itu, analisis min dan sisihan piawai pula digunakan untuk menentukan tahap kesihatan mental dan tahap motivasi pelajar sarjana semasa pembelajaran dalam talian sepanjang Covid-19. Seterusnya, jumlah skor min diperlukan untuk menentukan min skor rendah dengan min skor tinggi bagi setiap dimensi kesihatan mental dan motivasi. Skor min dibahagikan kepada tiga tahap iaitu rendah, sederhana dan tinggi mengikut saranan oleh Nik Mohd Rahimi (2004).

Jadual 4: Interpretasi min

\begin{tabular}{cc}
\hline Skor Min & Interpretasi \\
\hline $5.01-7.00$ & Tinggi \\
$3.01-5.00$ & Sederhana \\
$1.00-3.00$ & Rendah \\
\hline
\end{tabular}


Statistik inferensi pula digunakan untuk menganalisis data bagi menguji hipotesis kajian. Menurut Cohen \& Holliday (1982) pekali korelasi (r) yang diperoleh membolehkan pengkaji menerangkan perkaitan antara dua pemboleh ubah iaitu pemboleh ubah bebas dan pemboleh ubah bersandar. Sehubungan itu, Korelasi Pearson digunakan untuk mengkaji hubungan antara tahap kesihatan mental dan tahap motivasi pelajar semasa pembelajaran dalam talian sepanjang pandemik Covid-19. Kekuatan hubungan antara pemboleh ubah diinterpretasikan berdasarkan nilai pekali korelasi (r) seperti jadual 5 berikut:

Jadual 5: Interpretasi Korelasi

\begin{tabular}{cc}
\hline Pekali Korelasi $(\mathbf{r})$ & Interpretasi \\
\hline 0.00 & Tiada Korelasi \\
Kurang 0.19 & Sangat Rendah \\
$0.20-0.39$ & Rendah \\
$0.40-0.69$ & Sederhana \\
$0.70-0.89$ & Tinggi \\
$0.90-1.00$ & Sangat Tinggi \\
\hline
\end{tabular}

Sumber: Cohen \& Holliday (1982)

\section{Hasil Kajian}

\section{Demografi Responden}

Kajian ini telah melibatkan 242 orang pelajar UKM sebagai sampel kajian. Daripada sampel tersebut terdapat lebih ramai pelajar perempuan iaitu 192 orang $(80.2 \%)$ berbanding pelajar lelaki iaitu 48 orang (19.8\%). Majoriti responden kajian berumur dalam lingkungan 26 hingga 29 tahun ( $\mathrm{n}=78,32.2 \%)$. Hanya kurang daripada 5 peratus responden berumur dalam lingkungan 46 tahun dan ke atas $(n=5$, 2.1\%). Selain itu, agihan mengikut bangsa pula menunjukkan majoriti responden berbangsa Melayu iaitu seramai 195 orang pelajar (80.6\%). Dapatan kajian mengikut tahun pengajian pula menunjukkan majoriti responden dalam kajian ini adalah terdiri dari kalangan pelajar Tahun 2 pengajian sarjana ( $\mathrm{n}$ $=135,55.8 \%)$. Majoriti pelajar iaitu seramai 181 orang (74.8\%) mengikuti program pengajian jenis Mod C iaitu kerja kursus. Majoriti responden juga adalah pelajar sepenuh masa iaitu 167 orang (69\%) manakala, sebanyak $31 \%(n=75)$ orang pelajar mengikuti mod pengajian separuh masa. Seramai 201 $(83.1 \%)$ orang pelajar telah memperoleh CGPA yang cemerlang iaitu antara 3.51 hingga 4.00 dan hanya $2(0.8 \%)$ orang pelajar mendapat CGPA dibawah 2.00. Majoriti responden dalam kajian ini menggunakan WiFi sebagai sumber internet $(n=200,82.6 \%)$ dan hanya sebilangan kecil yang menggunakan data mudah alih $(\mathrm{n}=42,17.4 \%)$ semasa pembelajaran dalam talian sepanjang pandemik.

Jadual 6: Taburan Demografi Responden

\begin{tabular}{lccc}
\hline Demografi & Sub-profil & Frekuensi & Peratusan (\%) \\
\hline Jantina & Lelaki & 48 & 19.8 \\
& Perempuan & 192 & 80.2 \\
Umur & $22-25$ tahun & 39 & 16.1 \\
& $26-29$ tahun & 78 & 32.2 \\
& $30-33$ tahun & 42 & 17.4 \\
& $34-37$ tahun & 28 & 11.6 \\
& $38-41$ tahun & 28 & 11.6 \\
& $42-45$ tahun & 22 & 9.1 \\
Bangsa & 46 tahun ke atas & 5 & 2.1 \\
& Melayu & 195 & 80.6 \\
\hline
\end{tabular}



DOI: https://doi.org/10.47405/mjssh.v6i10.1100

Tahun Pengajian

Mod Program

Mod Pengajian

Pencapaian akademik (CGPA)

Sumber Internet

Cina
Lain-lain
Tahun 1
Tahun 2

Tahun 3

Mod A: Penyelidikan sahaja Mod B: Kerja Kursus \& Penyelidikan 51

Mod C: Kerja Kursus sahaja $\quad 181$

$\begin{array}{lll}\text { Sepenuh masa } & 167 & 69.0\end{array}$

$\begin{array}{lll}\text { Separuh masa } & 75 & 31.0\end{array}$

$\begin{array}{lll}0-2.00 & 2 & 0.8\end{array}$

$2.01-2.50$

$2.51-3.00$

$3.01-3.50$

$3.51-4.00$

Data mudah alih

Prabayar bulanan

$\mathrm{WiFi}$
$0 \quad 0$

$4 \quad 1.7$

$35 \quad 14.5$

$201 \quad 83.1$

$42 \quad 17.4$

67
27.7

$200 \quad 82.6$

\section{Tahap Kesihatan Mental Pelajar Sarjana UKM}

Jadual 7 menunjukkan min keseluruhan kesihatan mental bagi responden UKM adalah rendah iaitu 1.95. Dapatan kajian menunjukkan di antara tiga dimensi yang berada di tahap rendah ini, dimensi Kehilangan Keyakinan $(\min =2.48)$ mempunyai min tertinggi diikuti oleh Kebimbangan dan Kemurungan $(\min =1.75)$ dan akhir sekali adalah Disfungsi Sosial $(\min =1.60)$.

Jadual 7: Tahap kesihatan mental pelajar sarjana semasa pembelajaran dalam talian

\begin{tabular}{lccc}
\hline Dimensi Kesihatan Mental & Min & SP & Tahap \\
\hline Kebimbangan dan Kemurungan & 1.75 & 0.57 & Rendah \\
Disfungsi Sosial & 1.60 & 0.50 & Rendah \\
Kehilangan Keyakinan & 2.48 & 0.72 & Rendah \\
Keseluruhan (Kesihatan Mental) & $\mathbf{1 . 9 5}$ & $\mathbf{0 . 4 5}$ & Rendah \\
\hline
\end{tabular}

\section{Tahap Motivasi Pelajar Sarjana UKM}

Jadual 8 menunjukkan min keseluruhan motivasi responden adalah tinggi iaitu 5.64. Konstruk motivasi yang tertinggi ialah dimensi Nilai Tugasan $(\min =5.97)$ diikuti oleh dimensi Kawalan Kepercayaan Pembelajaran $(\min =5.93)$, Motivasi Ekstrinsik $(\min =5.81)$, Efikasi Kendiri Pembelajaran dan Prestasi $(\min =5.70)$, Motivasi Intrinsik $(\min =5.57)$ dan terendah adalah dimensi Kebimbangan Ujian $(\min =4.83)$.

Jadual 8: Tahap motivasi pelajar sarjana semasa pembelajaran dalam talian

\begin{tabular}{lccc}
\hline Dimensi Motivasi & Min & SP & Tahap \\
\hline Motivasi Intrinsik & 5.57 & 0.80 & Tinggi \\
Motivasi Ekstrinsik & 5.81 & 0.96 & Tinggi \\
Nilai Tugasan & 5.97 & 0.75 & Tinggi \\
Kawalan Kepercayaan Pembelajaran & 5.93 & 0.75 & Tinggi \\
Efikasi Kendiri Pembelajaran dan Prestasi & 5.70 & 0.81 & Tinggi \\
Kebimbangan Ujian & 4.83 & 1.15 & Sederhana \\
\hline Keseluruhan (Motivasi) & $\mathbf{5 . 6 4}$ & $\mathbf{0 . 6 2}$ & Tinggi \\
\hline
\end{tabular}


DOI: https://doi.org/10.47405/mjssh.v6i10.1100

\section{Hubungan antara Tahap Kesihatan Mental dan Tahap Motivasi Pelajar Sarjana semasa pembelajaran dalam talian sepanjang pandemik}

Bagi menentukan kesignifikanan tahap kesihatan mental dan tahap motivasi pelajar sarjana, hipotesis nul dibentuk dan diuji seperti berikut:

Hipotesis Nul 1: Tidak terdapat hubungan yang signifikan antara tahap kesihatan mental dengan tahap motivasi dalam kalangan pelajar sarjana UKM semasa pembelajaran dalam talian sepanjang pandemik Covid-19.

Jadual 9 menunjukkan keputusan ujian Korelasi Pearson bagi melihat hubungan antara tahap kesihatan mental dan tahap motivasi pelajar sarjana semasa pembelajaran dalam talian sepanjang pandemik Covid-19.

Berdasarkan analisis korelasi, dapatan menunjukkan terdapat hubungan yang signifikan antara tahap kesihatan mental dan tahap motivasi pelajar sarjana dengan nilai $r=0.146$ dan $\operatorname{sig}=0.023(p<0.05)$. Nilai $\mathrm{p}<0.05$ menunjukkan terdapat hubungan yang signifikan antara dua pemboleh ubah yang berkaitan. Kekuatan hubungan bagi tahap kesihatan mental dan tahap motivasi pelajar sarjana semasa pembelajaran dalam talian sepanjang pandemik Covid-19 adalah pada tahap positif sangat rendah. Oleh itu, hipotesis nul (Ho1) adalah gagal diterima.

Jadual 9: Hubungan antara Kesihatan Mental dengan Motivasi Pelajar Sarjana

\begin{tabular}{lrr}
\hline & \multicolumn{2}{c}{ Motivasi } \\
\hline & r & Sig. P \\
\hline Kesihatan Mental & 0.146 & 0.023 \\
\hline *. Pekali koratasi
\end{tabular}

*. Pekali korelasi signifikan pada aras 0.05 (dua ekor)

\section{Perbincangan Kajian}

Berdasarkan analisis deskriptif yang dijalankan, dapatan kajian mendapati bahawa pelajar sarjana UKM mempunyai tahap kesihatan mental yang rendah semasa pembelajaran dalam talian sepanjang pandemik Covid-19. Dimensi kebimbangan dan kemurungan, disfungsi sosial dan kehilangan keyakinan mempunyai skor min yang berada pada tahap rendah. Tahap kesihatan mental yang rendah membuktikan bahawa pelajar sarjana berada dalam keadaan yang normal, baik dan terkawal. Hal ini membuktikan bahawa pelajar sarjana UKM dapat menyesuaikan diri dengan platform pembelajaran dalam talian, dapat mengatasi masalah, dapat menumpukan perhatian, mampu membuat keputusan, memainkan peranan yang berguna dalam banyak perkara dan mempunyai kepercayaan diri yang tinggi semasa pembelajaran dalam talian (Goldberg \& Williams, 1988). Dapatan kajian ini bertepatan dengan kajian oleh Nidal et al. (2020) yang mendapati tahap kesihatan mental pelajar semasa pembelajaran dalam talian sepanjang pandemik berada pada tahap yang rendah iaitu baik. Dapatan kajian ini juga selari dengan dapatan kajian Rohana et al. (2021) yang menunjukkan bahawa pelajar senior di universiti kurang menghadapi masalah kesihatan mental berbanding dengan pelajar prasiswazah atau pelajar sarjana pada tahun pertama. Perkara ini dapat dilihat dari sudut kematangan mereka dalam menguruskan kesihatan mental sepanjang tempoh pengajian membuatkan pelajar-pelajar senior kurang terjejas secara fizikal dan mental daripada pelajar muda atau yang baharu memulakan pengajian di IPT.

Seterusnya, dapatan kajian mendapati bahawa pelajar sarjana UKM mempunyai tahap motivasi yang tinggi semasa pembelajaran dalam talian sepanjang pandemik Covid-19. Lima dimensi motivasi iaitu motivasi intrinsik, motivasi ekstrinsik, nilai tugasan, kawalan kepercayaan pembelajaran, serta efikasi kendiri pembelajaran dan prestasi mempunyai nilai min yang tinggi. Manakala, hanya satu dimensi motivasi iaitu dimensi kebimbangan ujian berada pada tahap yang sederhana. Ini merupakan dapatan yang positif terhadap tahap motivasi pelajar kerana pelajar turut bermotivasi untuk mendapatkan gred yang baik dalam program pengajian untuk meningkatkan keseluruhan gred purata dengan menggunakan cara pembelajaran yang betul dan sesuai. Dalam pada itu, pelajar juga bermotivasi dalam 
memahami kandungan subjek yang dibentangkan supaya mereka dapat mengaplikasikan apa yang dipelajari dalam program pengajian ini pada kursus lain (Pintrich et al., 1991). Dapatan kajian ini selari dengan dapatan kajian oleh Abdul Aziz dan Aida Zuraina (2020), Afif dan Fitrana (2020) dan Aguilera-Hermida (2020) yang mendapati bahawa motivasi pelajar semasa pembelajaran dalam talian berada pada tahap yang tinggi. Tahap motivasi yang tinggi menunjukkan pelajar mampu menerima konsep pembelajaran dengan baik dan mempunyai kebolehan untuk beradaptasi dengan pembelajaran dalam talian sepanjang pandemik (Abdul Aziz \& Aida Zuraina, 2020).

Selain itu, berdasarkan analisis inferensi Korelasi Pearson yang telah dijalankan, dapatan kajian menunjukkan bahawa terdapat hubungan yang signifikan dan positif antara tahap kesihatan mental dengan tahap motivasi dalam kalangan pelajar sarjana UKM sepanjang pembelajaran dalam talian semasa pandemik Covid-19. Hal ini menunjukkan, semakin baik dan normal tahap kesihatan mental seseorang pelajar, semakin tinggi tahap motivasi mereka semasa mengikuti pembelajaran dalam talian. Dapatan kajian ini selari dengan kajian Parinaz et al. (2021) yang mendapati terdapat hubungan yang signifikan dan positif antara kesihatan mental dengan motivasi pelajar sepanjang pembelajaran dalam talian semasa pandemik. Kesihatan mental dengan motivasi yang tinggi dalam kalangan pelajar adalah dua perkara yang sangat penting sepanjang pembelajaran dalam talian semasa pandemik. Hal ini kerana, kesihatan mental yang baik mampu meningkatkan motivasi pelajar semasa proses pembelajaran berlaku sama ada secara bersemuka ataupun secara dalam talian (Yasuhiro \& Su-Hie, 2021).

Secara keseluruhannya, dapatan kajian ini jelas membuktikan bahawa kesihatan mental adalah penting bagi meningkatkan motivasi pelajar agar mereka mampu beradaptasi dengan norma baharu dalam pendidikan iaitu menjalani pembelajaran secara dalam talian semasa pandemik Covid-19. Justeru, kajian ini menggambarkan pentingnya untuk mengekalkan tahap kesihatan mental yang baik supaya pelajar kekal sihat dan bermotivasi tinggi semasa pembelajaran dalam talian.

\section{Kesimpulan}

Kajian ini telah mengenal pasti tahap kesihatan mental dan tahap motivasi dalam kalangan pelajar sarjana bidang pendidikan di sebuah universiti penyelidikan di Lembah Klang iaitu Universiti Kebangsaan Malaysia (UKM). Kajian turut mengkaji hubungan antara tahap kesihatan mental dan tahap motivasi pelajar sarjana semasa pembelajaran dalam talian sepanjang pandemik Covid-19. Dapatan kajian ini jelas menunjukkan bahawa pelajar Sarjana Pendidikan di UKM mempunyai tahap kesihatan mental yang baik dan tahap motivasi yang sangat tinggi semasa pembelajaran dalam talian sepanjang pandemik dan terdapat hubungan yang signifikan dan positif antara tahap kesihatan mental dengan tahap motivasi pelajar.

Dalam usaha menjalankan kajian ini, pengkaji menghadapi beberapa kekangan seperti kesukaran untuk membuat perbandingan dari segi dapatan kajian dalam konteks Malaysia semasa pandemik. Manakala dari sudut pengumpulan data pula, pengkaji terpaksa menggunakan pendekatan alternatif iaitu dengan menggunakan kaedah tinjauan dengan mengedarkan soal selidik secara dalam talian dan ini telah menghadkan proses kutipan data kerana pelajar sibuk beradaptasi dengan PdP dalam talian dan pengisian soal selidik tidak menjadi urusan penting ketika itu. Seterusnya, kajian ini hanya tertumpu kepada pelajar sarjana di Fakulti Pendidikan, UKM dan tidak dapat digeneralisasikan kepada semua pelajar Sarjana Pendidikan universiti awam di Malaysia. Oleh itu, kajian masa hadapan perlu melibatkan pelajar sarjana di universiti penyelidikan atau di Fakulti Pendidikan universiti awam dan swasta di Malaysia agar dapatan kajian daripada sampel yang lebih besar dapat digeneralisasikan untuk membuat keputusan yang boleh mempengaruhi dasar atau strategi PdP untuk latihan pendidikan guru. Selain itu, pengkaji mencadangkan agar kajian lanjutan dapat mengkaji dimensi-dimensi kesihatan mental dan motivasi lebih mendalam dengan menggunakan instrumen yang berbeza agar kajian menjadi lebih efektif dan meluas.

Kajian ini sedikit sebanyak dapat memberi sumbangan kepada pelajar, pensyarah di Fakulti Pendidikan UKM khususnya dan Fakulti Pendidikan di universiti awam amnya dalam memahami kepentingan menjaga kesihatan mental dengan baik semasa pandemik. Selain itu, kajian ini memberi makluman 
penting tentang keperluan pakar pendidikan yang menjalani program pengajian Sarjana Pendidikan untuk sentiasa peka terhadap kesihatan mental dan motivasi kendiri agar mereka dapat menjalankan tugas sebagai pelajar dan pendidik di sekolah dengan baik. Sebagai pendidik, mereka adalah contoh atau model kepada murid dan menjadi agen perubahan yang signifikan kepada pelajar di sekolah. Oleh itu, mereka perlu mempunyai motivasi yang tinggi serta tahap kesihatan mental yang baik. Pihak UKM juga berperanan dalam menyediakan perkhidmatan psikologi atau kaunseling dan disesuaikan dengan situasi atau keperluan pandemik bagi mengurangkan masalah kesihatan mental dan meningkatkan motivasi pelajar semasa pembelajaran dalam talian. Dapatan kajian ini turut memberi implikasi kepada keperluan komunikasi yang lebih luas dan berkesan bagi mengurangkan masalah kesihatan mental dalam kalangan pelajar pascasiswazah kerana semasa PdP, mereka bukan hanya perlu menguruskan kerja hakiki di sekolah atau pejabat tetapi juga menguruskan hal keluarga. Implikasi kajian turut menggalakkan pihak pengurusan UKM untuk terus merancang serta mengawal keadaan kesihatan mental pelajar dengan beberapa mekanisme daya tindak seperti perubahan dalam gaya hidup, corak pemikiran yang resilien dan minda positif (Abdul Rashid et al., 2020a) bagi memastikan emosi pelajar pascasiswazah yang stabil dan terkawal sepanjang pembelajaran dalam talian semasa pandemik.

\section{Rujukan}

Abdul Aziz Ishak \& Aida Zuraina Mir Ahmad Talaat. (2020). Pembelajaran atas talian: tinjauan terhadap kesediaan dan motivasi dalam kalangan pelajar Diploma logistik dan pengurusan rantaian bekalan, Politeknik Seberang Perai, Pulau Pinang. Jurnal Dunia Pendidikan, 2(4), 6882.

Abdul Rashid Abdul Aziz, Nurhafizah Mohd Sukor \& Nor Hamizah Ab Razak. (2020a). Wabak Covid-19: pengurusan aspek kesihatan mental semasa norma baharu. International Journal of Social Science Research, 2(4), 156-174.

Abdul Rashid Abdul Aziz, Amin Al Haadi Shafie, Umi Hamidaton Mohd Soffian Lee, Raja Nur Syafiqah Raja Ashaar. (2020b). Strategi pembangunan aspek kesejahteraan kendiri bagi mendepani tekanan akademik semasa wabak Covid-19. Malaysian Journal of Social Sciences and Humanities 5(12), 16-30.

Aidos K. Bolatov, Telman Z. Seisembekov, Altynay Zh. Askarova, Raushan K. Baikanova, Dariga S. Smailova \& Elisa Fabbro. (2020). Online-learning due to Covid-19 improved mental health among medical students. Medical Science Educator, 1-10.

Afif Ikhwanul Muslimin \& Fitrana Harintama. (2020). Online learning during pandemic: students' motivation, challenges, and alternatives. Loquen: English Studies Journal, 13(2), 60-68.

Amir, L. R., Tanti, I., Maharani, D. A., Wimardhani, Y. S., Julia, V., Sulijaya, B., \& Puspitawati, R. (2020). Student perspective of classroom and distance learning during Covid-19 pandemic in the undergraduate dental study program Universitas Indonesia. BMC Medical Education, 20(1), $1-8$.

Amir Vahedian-Azimi, Malihe Sadat Moayed, Farshid Rahimibashar, Sajad Shojaei, Sara Ashtari \& Mohamad Amin Pourhoseingholi. (2020). Comparison of the severity of psychological distress among four groups of an Iranian population regarding COVID-19 pandemic. BMC Psychiatry, $20(1), 402$.

Ana, A., Minghat, A. D., Purnawarman, P., Saripudin, S., Muktiarni, M., Dwiyanti, V., \& Mustakim, S.S. (2020). Students' perceptions of the twists and turns of e- learning in the midst of the covid 19 outbreak. Revista Romaneasca pentru Educatie Multidimensionala, 12 (1Sup2), 15-26.

Andi Wahyu Irawan, Dwisona \& Mardi Lestari. (2020). Psychological impacts of students on online learning during the pandemic Covid-19. Jurnal Bimbingan dan Konseling, 7(1), 53-60.

Aguilera-Hermida, A., P. (2020). College students' use and acceptance of emergency online learning due to Covid-19. International Journal of Educational Research Open, 1, 1-8.

Azman, N., \& Abdullah, D. (2021). A critical analysis of Malaysian Higher Education Institutions' response towards Covid-19: sustaining academic program delivery. Journal of Sustainability Science and Management, 16(1), 70-96.

Bandura, A. (1971). Social learning theory. New York: General Learning Press.

Bao, Y., Sun Y., Meng, S., Shi J., \& Lu, L. (2020). 2019-nCoV epidemic: address mental health care to empower society. The Lancet, 395, e37-e38. 
Bernard, H.W. (1965). Psychology of learning. New York: Mc Graw-Hill Book Company.

Bluman, A. G. (2017). Elementary Statistics: A Step By Step Approach. 10th Ed. United States: McGraw-Hill Education.

Cao, W., Fang, Z., Hou, G., Han, M., Xu X., Dong, J., \& Zheng, J. (2020). The psychological impact of the Covid-19 epidemic on college students in China. Psychiatry Research, 287, 2-5.

Casagrande, M., Favieri, F., Tambelli, R., \& Forte, G. (2020). The enemy who sealed the world: Effects quarantine due to the Covid-19 on sleep quality, anxiety, and psychological distress in the Italian population. Sleep Medicine, 75, 12-20.

Cohen, L., \& Holliday, M. (1982). Statistics for Social Sciences. Harper \& Row: London.

Creswell, J. W., (2014). Research Design: Qualitative, Quantitative, and Mixed Methods Approaches. ( $4^{\text {th }}$ ed.). Thousand Oaks, California: SAGE Publications.

Day, M. C., Kelley, H. M., Browne, B. L., \& Kohn, S. J. (2020). Assessing motivation and learning strategy usage by dually enrolled students. Smart Learning Environments, 7(22), 1-19.

Deblina Roya, Sarvodaya Tripathya, Sujita Kumar Kara, Nivedita Sharmaa, Sudhir Kumar Vermaa \& Vikas Kaushalb. (2020). Study of knowledge, attitude, anxiety \& perceived mental healthcare need in Indian population during Covid-19 pandemic. Asian Journal of Psychiatry, 51, 1-7.

Duncan, K., Kenworthy, A. \& McNamara, R. (2012). The Effect of Synchronous and Asynchronous Participation on Students' Performance in Online Accounting Courses. Accounting Education, 21, 1-19.

Ellen Chung, Norlina Mohamed Noor \& Vloreen Nity Mathew. (2020). Are You Ready? An Assessment of Online Learning Readiness among University Students. International Journal of Academic Research in Progressive Education and Development, 9(1), 301-317.

Fakhruddin Khosim \& Mohd Isha Awang. 2020. Validity and reliability of the MSLQ Malay version in measuring the level of motivation and self-regulated learning. International Journal of Scientific \& Technology Research, 9(02), 903-905.

Fraenkel, J. R., \& Wallen, N. E. (1993). How to design and evaluate research in education (2nd ed.). Boston, MA: McGraw Hill.

Gao, J., Zheng, P., Jia, Y., Chen, H., Mao, Y., Chen, S., \& Dai, J. (2020). Mental health problems and social media exposure during Covid-19 outbreak. PLoS ONE, 215, e0231924.

Giesbers, B., Rienties, B., Tempelaar, D. \& Gijselaers, Wim. (2013). A dynamic analysis of the interplay between asynchronous and synchronous communication in online learning: The impact of motivation. Journal of Computer Assisted Learning, https://doi.org/10.1111/jcal.12020.

Goldberg, D. P. (1972). The detection of psychiatric illness by questionnaire. New York: Oxford Univ Press.

Goldberg, D., \& Williams, P. (1988). A user's guide to the General Health Questionnaire. Windsor, UK: NFER-Nelson.

Gredler, M.E., Broussard, S.C., \& Garrison, M.E.B. (2004). The relationship between classroom motivation and academic achievement in elementary school aged children. Family and Consumer Sciences Research Journal, 33, 106-120.

Hairani Lubis, Ayunda Ramadhani \& Miranti Rasyid. (2021). Stres akademik mahasiswa dalam melaksanakan kuliah daring selama masa pandemi Covid 19. Psikostudia Jurnal Psikologi, 10 (1), 31-39.

Hair, J.F., Black, W.C., Babin, B.J., \& Anderson, R.E. (2010). Multivariate Data Analysis. Seventh Edition. New York: Pearson.

Holmes, E. A., O'Connor, R. C., Perry, V. H., Tracey, I., Wessely, S., Arseneault, L., Ballard, C., Christensen, H., Cohen Silver, R., Everall, I., Ford, T., John, A., Kabir, T., King, K., Madan, I., Michie, S., Przybylski, A. K., Shafran, R., Sweeney, A., Worthman, C. M., ... Bullmore, E. (2020). Multidisciplinary research priorities for the COVID-19 pandemic: a call for action for mental health science. The lancet Psychiatry, 7(6), 547-560.

Izyan Izzati Kamsani \& Aishah Mahat. (2021). Covid 19: Impak e-pembelajaran terhadap kesihatan pelajar universiti. Jurnal Dunia Pendidikan, 3(3), 53-60.

Kecojevic, A., Basch, C. H., Sullivan, M., \& Davi, N. K. (2020). The impact of the Covid-19 epidemic on mental health of undergraduate students in New Jersey, cross-sectional study. PLoS ONE, 15(9), 1-16. 
Khaled Seetan, Mohammad Al-Zubi, Yousef Rubbai, Mohammad Athamneh, Almu'atasim Khamees \& Tala Radaideh. (2021). Impact of COVID-19 on medical students' mental wellbeing in Jordan. PLOS ONE, 16(6), e0253295.

Kimble, G. A. (1984). Psychology's two cultures. American Psychologist, 9,833-839.

Krejcie, R.V., \& Morgan, D.W. (1970). Determining sample size for research activities. Educational and Psychological Measurement, 30, 607-610.

Letchumanan Shanmugam, Siti Fatimah Yassin \& Fariza Khalid. (2019). Enhancing students' motivation to learn computational thinking through Mobile Application Development Module (M-CT). International Journal of Engineering and Advanced Technology (IJEAT), 8(5), 12931303.

Mahiswaran Selvanathan, Nur Atikah Mohamed Hussin \& Noor Alyani Nor Azazi. (2020). Students learning experiences during Covid-19: work from home period in Malaysian Higher Learning $\begin{array}{llll}\text { Institutions. } \quad \text { Teaching } & \text { Public } & \text { Administration, } & \end{array}$ https://doi.org/10.1177/0144739420977900

Maila Rahiem. (2021). Remaining motivated despite the limitations: University students' learning propensity during the COVID-19 pandemic. Children and youth services review, 120, 105802.

Manwell, L. A., Barbic, S. P., Roberts, K., Durisko, Z., Lee, C., Ware, E., \& McKenzie, K. (2015). What is mental health? Evidence towards a new definition from a mixed methods multidisciplinary international survey. BMJ Open, 5, 1-11.

Marielle Wathelet, Stéphane Duhem, Guillaume Vaiva, Thierry Baubet, Enguerrand Habran, Emilie Veerapa, Christophe Debien, Sylvie Molenda, Mathilde Horn, Pierre Grandgenèvre, CharlesEdouard Notredame \& Fabien D'Hondt. (2020). Factors associated with mental health disorders among university students in France confined during the Covid-19 pandemic. JAMA Network Open, 3(10), e2025591.

Matthew H. E. M. Browning, Lincoln R. Larson, Iryna Sharaievska, Alessandro Rigolon, Olivia McAnirlin, Lauren Mullenbach, Scott Cloutier, Tue M. Vu, Jennifer Thomsen, Nathan Reigner, Elizabeth Covelli Metcalf, Ashley D'Antonio, Marco Helbich, Gregory N. Bratman, Hector Olvera Alvarez. (2021). Psychological impacts from COVID-19 among university students: Risk factors across seven states in the United States. PLOS ONE, 16(1), e0245327.

Mazidah Musa \& Nor Aidawati Abdillah. (2021). Penggunaan Google Meet dalam proses pengajaran dan pembelajaran di Politeknik Sultan Mizan Zainal Abidin. International Journal of Modern Education, 3(8), 104-113.

Muhammad Irfan, Faizah Shahudin, Vincent James Hooper, Waqar Akram \& Rosmaiza Abdul Ghani. (2020). The psychological impact of coronavirus on university students and its socio-economic determinants in Malaysia. doi: https://doi.org/10.1101/2020.10.27.20220723

Muhamad Saiful Bahri Yusoff, Ahmad Fuad Abdul Rahim \& Mohd Jamil Yaacob. (2010). The sensitivity, specificity and reliability of the malay version 12-items General Health Questionnaire (GHQ-12) in detecting distressed medical students. ASEAN Journal of Psychiatry, 11(21), 36-43.

Muhammad Salehan Alhafiz Mat Wajar \& Rohana Hamzah. 2020. Model Kebahagiaan Hidup Pelajar Universiti Berdasarkan Faktor Kesihatan Mental, Kecerdasan Spiritual dan Demografi. Malaysian Journal of Social Sciences and Humanities, 5(11), 17-32.

Munirah Salleh, Mohd Faisal Jamaludin, Noor Syaheeda Mohd Safie \& Julia Mohd Yusof. (2021). injauan Keberkesanan Pembelajaran Secara dalam Talian Ketika Pandemik Covid-19: Perspektif Pelajar Sains Kejuruteraan Politeknik Ibrahim Sultan. Jurnal Dunia Pendidikan, 3(1), 374-384.

Nidal Drissi, Ayat Alhmoudi, Hana Al Nuaimi, Mahra Alkhyeli, Shaikha Alsalami \& Sofia Ouhbi. (2020). Investigating the Impact of Covid-19 Lockdown on the Psychological Health of University Students and Their Attitudes Toward Mobile Mental Health Solutions: Two-Part Questionnaire Study. JMIR Formative Research, 4(10), 1-14.

Norazila Mat, Noridayu Idris, Nur Atiqah Abdullah, Zaleha Yazid \& Jamsari Alias. (2018). hubungan antara beban kerja, faktor peribadi, dan pembelajaran-e terhadap tahap tekanan di kalangan Gen-Y. Jurnal Personalia Pelajar, 21(2), 23-35.

Norhazirah Mustaffa. (2020). Mengatasi kebimbangan semasa pandemik covid-19 dengan pendekatan Teori Rational Emotive Behaviour Therapy (REBT). Malaysian Journal of Social Sciences and Humanities, 5(11), 10-16. 
Nik Mohd Rahimi Nik Yusoff. (2004). Kemahiran mendengar bahasa Arab: Satu kajian di Sekolah Menengah Kerajaan Negeri. Unpublished Ph.D, Universiti Kebangsaan Malaysia, Bangi.

Nur Hazirah Hairia'an \& Masayu Dzainudin. (2020). Pengajaran dan pemudahcaraan dalam talian semasa perintah kawalan pergerakan. Jurnal Pendidikan Awal Kanak-kanak Kebangsaan, 9, 1828.

O'Connor, D. B., Aggleton, J. P., Chakrabarti, B., Cooper, C. L., Creswell, C., Dunsmuir, S., Fiske, S. T., Gathercole, S., Gough, B., Ireland, J. L., Jones, M. V., Jowett, A., Kagan, C., KaranikaMurray, M., Kaye, L. K., Kumari, V., Lewandowsky, S., Lightman, S., Malpass, D.,

Armitage, C. J. (2020). Research priorities for the COVID-19 pandemic and beyond: A call to action for psychological science. British Journal of Psychology, 111(4), 603-629.

Odriozola-González P., Planchuelo-Gómez Á., Irurtia, M. J., \& Luis-García, R. E. (2020). Psychological effects of the Covid-19 outbreak and lockdown among students and workers of a Spanish university. Psychiatry Research, 290, 1-8.

Pallant, Julie F. (2013). SPSS survival manual: A step by step guide to data analysis using IBM SPSS. Crows Nest, N.S.W: Allen \& Unwin.

Parinaz Mahdavi, Adib Valibeygi, Masoud Moradi \& Shahram Sadeghi. (2021). Relationship between achievement motivation, mental health and academic success in university students. International Quarterly of Community Health $\quad$ Education, $\quad$ Retrieved from https://doi.org/10.1177/0272684X211025932

Pintrich, P. R., Smith, D. A. F., Garcia, T., \& McKeachie, W. J. (1991). A manual for the use of the Motivated Strategies for Learning Questionnaire (MSLQ). Ann Arbor: National Center for Research to Improve Postsecondary Teaching and Learning, The University of Michigan.

Ryan, R.M., \& Deci, E.L. (2000). Intrinsic and extrinsic motivations: classic definitions and new directions. Contemporary Educational Psychology, 25(1), 54-67.

Reeve, J., \& Deci, E. L. 1996. Elements of the competitive situation that affect intrinsic motivation. Personality and Social Psychology Bulletin, 22(1), 24-33.

Rigotti, T., De Cuyper, N., \& Sekiguchi, T. (2020). The Corona Crisis: What Can We Learn from Earlier Studies in Applied Psychology? Applied Psychology, 0 (0), 1-6.

Rohana Hamzah, Hafiz Salehan, Ahmad Muhaimin, Hadijah Ahmad, Mohd. Suhardi Mad Jusoh \& Fatmawati Latada. (2021). Kesihatan mental dan kecerdasan spiritual mahasiswa di universiti; satu perbandingan antara tahun pengajian dan agama. International Journal of Humanities Technology and Civilization (IJHTC), 10(3), 18-35.

Sahu, P. (2020). Closure of universities due to coronavirus disease 2019 (Covid-19): impact on education and mental health of students and academic staff. Cureus, 12(4), e7541.

Samir Abou El-Seoud, M., Taj-Eddin, I. A. T. F., Seddiek, N., El-Khouly, M. M., \& Nosseir, A. (2014). E-learning and Students' Motivation: A Research Study on the Effect of E-learning on Higher Education. International Journal of Emerging Technologies in Learning, 9(4), 20-26.

Sekaran, U. \& Bougie, R. (2013). Research Methods for Business. (6th ed.). West Sussex: John Wiley \& Sons.

Shamzaeffa Samsudin \& Kevin Tan Chee Hong. (2016). Hubungan antara tahap kesihatan mental dan prestasi pelajar sarjana muda: satu kajian di Universiti Utara Malaysia. Jurnal Sains Kesihatan Malaysia, 14(1), 11-16.

Sheela Sundarasen, Karuthan Chinna, Kamilah Kamaludin, Mohammad Nurunnabi, Gul Mohammad Baloch, Heba Bakr Khoshaim, Syed Far Abid Hossain \& Areej Sukayt. (2020). Psychological impact of Covid-19 and lockdown among university students in Malaysia: implications and policy recommendations. International Journal of Environmental Research and Public Health, 17(17), 6206.

Shivangi Dhawan. (2020). Online learning: a panacea in the time of Covid-19 crisis. Journal of Educational Technology Systems, 49(1), 5-22.

Silvana Galderisi, Andreas Heinz, Marianne Kastrup, Julian Beezhold \& Norman Sartorius. (2015). Toward a new definition of mental health. World Psychiatry, 14(2), 231-233.

Son, C., Hegde, S., Smith, A., Wang, X., \& Sasangohar, F. (2020). Effects of Covid-19 on college students' mental health in the United States: interview survey study. Journal of Medical Internet Research, 22(9), e21279.

United Nations Educational, Scientific and Cultural Organization (UNESCO). (2020). Retrieved from: https://en.unesco.org/Covid19/educationresponse 
Wang, G., Zhang, Y., Zhao, J., Zhang, J., \& Jiang, F. (2020). Mitigate the effects of home confinement on children during the Covid-19 outbreak. The Lancet, 395, 945- 947.

WHO. (2004). Promoting mental health: concepts, emerging evidence, practice (Summary Report). Geneva: World Health Organization.

WHO. (2004). Prevention of mental disorders: effective interventions and policy options. Summary Report. A Report of the World Health Organization, Department of Mental Health and Substance Abuse in Collaboration with The Prevention Research Centre of the Universities of Nijmegen and Maastricht. Geneva: World Health Organization.

Yang, Y., Li W., Zhang, Q., Zhang, L., Cheung, T., \& Xiang, Y.T. (2020). Mental health services for older adults in China during the Covid-19 outbreak. Lancet Psychiatry, 7, e19.

Yani Fitriyani, Irfan Fauzi \& Mia Zultrianti Sari. (2020). Motivasi belajar mahasiswa pada pembelajaran daring selama pandemik Covid-19. Jurnal Kependidikan, 6(2), 165-175.

Yasuhiro Kotera \& Su-Hie Ting. (2021). Positive psychology of Malaysian University Students: impacts of engagement, motivation, self-compassion, and well-being on mental health. International Journal of Mental Health and Addiction, 19, 227-239

Zacher, H., \& Rudolph, C. W. (2021). Individual differences and changes in subjective wellbeing during the early stages of the Covid-19 pandemic. American Psychologist, 76(1), 50-62.

Zaliza Mohamad Nasira \& Zaitul Azma Zainon Hamzah. Sikap dan motivasi pelajar terhadap pembelajaran Bahasa Melayu. Procedia - Social and Behavioral Sciences, 134, 408 - 415.

Zamry Ahmad Mokhtar \& Nur Ashikin Lakman. (2021). Peralihan dari pembelajaran bersemuka ke pembelajaran secara atas talian untuk subjek mechanics of civil engineering structures semasa pandemik Covid-19. Journal Of Social Science And Humanities, 2(2), 11-18.

Zhang, J., Wu W., Zhao, X., \& Zhang, W. (2020). Recommended psychological crisis intervention response to the 2019 novel coronavirus pneumonia outbreak in China: a model of West China Hospital. Precision Clinical Medicine, 3, 3-8. 